\title{
Two lesser known causes of hyperkalaemia
}

\author{
Priyankara W D D ${ }^{1}$ \\ Journal of the Ceylon College of Physicians, 2019, 50, 84-86
}

\section{Introduction}

Hyperkalaemia is a common electrolyte disorder which is potentially life-threatening. The extracellular potassium is balanced and kept within the physiologic range by intracellular homeostatic mechanisms. Hyperkalaemia can lead to cardiac arrest secondary to bradycardia, atrio-ventricular block and ventricular arrhythmias. Chronic kidney disease, rhabdomyolysis, medications such as renin angiotensin aldosterone system inhibitors and non-steroidal anti-inflammatory drugs are well known to raise the serum potassium level. We describe two cases of life-threatening hyperkalaemia which physicians should be aware of.

\section{Case presentation}

\section{Case1}

A 64-year-old man was being mechanically ventilated in the intensive care unit (ICU) due to type 2 respiratory failure following Guillain-Barré syndrome. In addition, he had diabetes mellitus and acute kidney injury on chronic kidney disease for which he was on regular haemodialysis. On the $17^{\text {th }}$ day, the nurse in charge of the patient was requested to administer 100 $\mathrm{mg}$ of intravenous suxamethonium with the intention of muscle relaxation for nasogastric tube insertion as the patient was struggling while attempting the procedure. Within minutes of intravenous injection, he developed bradycardia and asystolic cardiac arrest. Cardio pulmonary resuscitation was commenced. Immediate blood gas analysis showed potassium level $\left(\mathrm{K}^{+}\right)$of $10 \mathrm{mmol} / \mathrm{L}$. Blood gas analysis done 2 hours prior to the suxamethonium injection showed $\mathrm{K}^{+}$level within the normal range $(4.2 \mathrm{mmol} / \mathrm{L})$. Hyperkalaemia was managed with repeated boluses of intravenous (IV) calcium gluconate and soluble insulin with 50\% dextrose. He received 2 cycles of IV adrenaline and return of spontaneous circulation was achieved in 6 minutes.

\section{Case 2}

A 45-year-old man was admitted with an acute febrile illness and acute kidney injury (AKI). He was suspected to have severe leptospirosis and transferred to the ICU due to myocarditis, shock, and AKI. Continuous renal replacement therapy was commenced for AKI as his haemodynamic parameters were unstable. Over the next 3 days, his blood pressure improved and vasopressors were weaned off. However, he required renal support with haemodialysis due to on-going AKI. On day 5 in the ICU, he underwent 3hour haemodialysis with blood flow rate of $150 \mathrm{ml} / \mathrm{min}$ and dialysate flow rate $300 \mathrm{ml} / \mathrm{min}$, (with no ultra-filtrate) as his $\mathrm{K}^{+}$remained high $(7.8 \mathrm{mmol} / \mathrm{L})$. Hyperkalaemia was managed medically before the haemodialysis. However, he went into cardiac arrest 30 minutes after the haemodialysis and cardio-pulmonary resuscitation was commenced immediately. The blood gas analysis done during the cardiac arrest showed blood $\mathrm{K}^{+}$of 7.2 $\mathrm{mmol} / \mathrm{l}$. Hyperkalaemia was managed with repeated boluses of intravenous calcium gluconate, soluble insulin with 50\% dextrose and 8.4\% NaHCO3.

\section{Discussion}

Potassium is a small molecule that passes easily through cellular membranes. It is mainly distributed in the intracellular fluid at concentrations of 140 to 150 $\mathrm{mmol} / \mathrm{L}$ and in the extracellular fluid at concentrations of 3.5 to $5 \mathrm{mmol} / \mathrm{L}$. Hyperkalaemia can give rise to cardiac depression leading to bradycardia and atrioventricular block and hyperexcitability leading to ventricular arrhythmias ${ }^{1}$.

\section{Case 1}

Suxamethonium (Succinylcholine, SCh) is the drug of choice for rapid tracheal intubation during the

Key words: hyperkalaemia, suxamethonium, haemodialysis

${ }^{1}$ Consultant Intensivist, National Hospital, Sri Lanka.

Correspondence: PWDD, e-mail: dilsh123@gmail.com

This is an open-access article distributed under the terms of the Creative Commons Attribution License, which permits unrestricted use, distribution, and reproduction in any medium, provided the original author and source are credited. 
induction of anaesthesia. It has a rapid onset (1 minute) and short duration of action (7-8 minutes). SCh binds to the nicotinic acetylcholine receptors (AChRs) at the neuro-muscular junction and acts as a depolarizing muscle relaxant. As a result, there is an influx of $\mathrm{Na}+$ and efflux of $\mathrm{K}^{+}$out of the cells ${ }^{2}$. In healthy individuals SCh may result in a mild and transient hyperkalaemia, approximately 0.5-1.0 mEq/L, which occurs within 3-5 minutes after the IV administration. The effect may last up to $10-15$ minutes $^{3}$.

In certain pathological states however, there is an up regulation of the AChRs (Table 1 ). The depolarization of these AChRs that spread throughout the muscle membrane can cause severe $\mathrm{K}^{+}$efflux from the muscle, leading to hyperkalaemia.

Table 1.

\section{Pathological conditions with potential for hyperkalaemia with Succinylcholine ${ }^{5}$}

Upper or lower motor neurone denervation

Chemical denervation (muscle relaxants, drugs, clostridium toxins)

Immobilization

Direct muscle trauma, tumour or inflammation

Thermal trauma

Diffuse muscular atrophy

Severe infection

AChRs are located only in the neuromuscular junctional areas of the normally innervated muscle. In pathological conditions given in table 1 there is a potential to up-regulate (increase) these receptors throughout the muscle membrane. The up-regulation of AChRs could occur within hours of denervation. Immobilization itself may cause up-regulation and redistribution of these receptors in the extra-junctional areas as early as 6-12 h. However, the up-regulation is not great enough to cause hyperkalaemia with SCh within 24 to 48 hours of immobilization/denervation. Therefore, it is advisable to avoid the use of SCh beyond 48 to 72 hours of denervation/immobilization ${ }^{4,5}$. In such situations non-depolarising muscle relaxants such as rocuronium, atracurium should be used.
Although hyperkalaemia lasts less than 15 minutes in majority, in some instances, reversal to normokalaemia may take much longer. Therefore, cardiopulmonary resuscitation should be continued as long as necessary and IV calcium gluconate should be repeated till the ECG becomes normal.

\section{Case 2}

Haemodialysis is an effective modality to treat hyperkalaemia through diffusion of $\mathrm{K}^{+}$from plasma into the dialysate fluid. The effectiveness of solute clearance depends on $\mathrm{Kt} / \mathrm{V}$ which is a measure of the dose of dialysis given for a single dialysis. $\mathrm{K}, \mathrm{t}, \mathrm{V}$, represents the amount of urea clearance, total treatment time, total volume of plasma within the body that urea is distributed respectively ${ }^{6}$. Therefore, clearance of small molecules like $\mathrm{K}^{+}$will depend mainly on the above factors. At the end of dialysis, a "rebound" in the blood level of $\mathrm{K}^{+}$could occur due to the diffusion of $\mathrm{K}^{+}$from the intracellular fluid (ICF) to extracellular fluid (ECF). This is aggravated if the $\mathrm{K}^{+}$is pushed into the cells by medical treatment immediately prior to the haemodialysis. This rebound effect depends also on the capacity of the solute to diffuse, diffusion barriers, tissue perfusion, and pre-dialysis concentrations of the solute?.

The dialysis prescription (adequate time, blood flow rate, dialysate flow rate) is of paramount importance to make certain adequate solute clearance. Furthermore, in severe hyperkalaemia, when haemodialysis is used, the aim should be to lower the $\mathrm{K}^{+}$not only into the normal range, but to bring it down to a lower safe limit and should be monitored during as well as after dialysis.

\section{Conclusions}

Hyperkalaemia is a potentially life-threatening electrolyte disorder. Despite the frequent occurrence in medical patients, sometimes hyperkalaemia may go unnoticed by the attending physician. Lack of awareness on less common but potential causes such as Sch-induced hyperkalaemia and rebound hyperkalaemia following haemodialysis, could lead to fatal outcomes.

\section{References}

1. Weisberg LS. Management of severe hyperkalaemia. Critical Care Medicine 2008; 36(12): 3246-51.

2. Miller R. Will succinylcholine ever disappear? Anesth Analg 2004; 98:1674-5. 
3. Thapa S, Brull SJ. Succinylcholine-induced hyperkalaemia in patients with renal failure: An old question revisited. Anesth Analg 2000; 91: 237-41.

4. Fergusson RJ, Wright DJ, Willey RF, Crompton GK, Grant IW. Suxamethonium is dangerous in polyneuropathy. Br Med J (Clin Res Ed). 1981; 282(6260): 298-9. doi:10.1136/ bmj.282.6260.298.

5. Martyn JAJ, Richtsfeld M, Succinylcholine-induced hyperkalaemia in acquired pathologic states. Anesthesiology 2006; 104: 158-69.

6. Jindal K, Chan CT, Deziel C, et al. Hemodialysis Adequacy in Adults. JASN 2006: 17 (3 suppl 1): S4-S7.

7. Buemi M, Coppolino G, Bolignano D, et al. Arrhythmias and Hemodialysis: Role of Potassium and New Diagnostic Tools. Renal Failure 2009; 31: 75-80. 